\title{
Basic Conception of Research on Construction of Rural Logistics System in Hunan Province Based on Rural Revitalization Strategy*
}

\author{
Shijun Yuan \\ Hunan Modern Logistics College \\ Hunan University of Technology and Business \\ Hunan Modern Logistics Research Base \\ Changsha, China
}

\begin{abstract}
The report of the 19th National Congress of the CPC and the No. 1 Document of the Central Committee of 2018 both emphasized the need to vigorously implement the rural revitalization strategy. The revitalization of the countryside cannot be separated from the prosperity of the industry. The prosperity of the industry needs the support of logistics services. Based on the perspective of the rural revitalization strategy, this paper proposes the basic ideas for the research on the construction of rural logistics system in Hunan Province.
\end{abstract}

Keywords—rural revitalization; logistics system; conception

\section{INTRODUCTION}

"Opinions of the General Office of the State Council on Further Promoting Logistics Cost Reduction and Efficiency Improvement to Promote the Development of the Real Economy" (Promulgated by the General Office of the State Council [2017] No. 73), the National Development and Reform Commission's "Special Action Plan for Cost and Cost Efficiency of the Logistics Industry (2016-2018)", the "Medium and Long-term Development Plan for the Development of the Logistics Industry (2014-2020)" (issued by the State Council [2014] No. 42) and the 2017 "Hunan Provincial People's Government Work Report" proposed the strategy deployment of "improving the county-level three-level logistics distribution system". At the same time, the report of the Nineteenth National Congress of the CPC and the No. 1 Document of the Central Committee of 2018 both emphasized the need to vigorously implement the strategy of rural revitalization and put forward the general requirements of "prosperous industries, ecological livability, rural civilization, effective governance, and wealthy life". The construction of rural logistics system in Hunan Province has far-reaching effects on the development of rural industries, increasing farmers' income, ecological civilization and happy life. Therefore, the research of this topic is of great strategic

*Fund: The 2018 Hunan Provincial Philosophy and Social Science Foundation Base Project "Research on the Construction of Hunan Rural Logistics System Based on Rural Revitalization Strategy" (18JD43); Hunan Provincial Social Science Achievement Evaluation Committee's project "Research on Rural Logistics Development Countermeasures System Based on Rural Revitalization Strategy" (XSP19YBC277). significance and great application value.

\section{RESEARCH ON RURAL LOGISTICS IN FOREIGN COUNTRIES}

Developed countries have established relatively complete circulation management systems, including sound infrastructure, reasonable circulation organization models, sound policy support systems, and advanced circulation technologies. Relevant research on rural circulation is also earlier, mainly focusing on the research of agricultural product circulation. Such as "Report of the Industrial Commission on the Distribution of Farm Products" by John E Croweli in 1901 and "The Marketing of Farm Product" by L. D. H. Weld. The former mainly discusses the influencing factors and the cost of agricultural product distribution, and the latter mainly discusses the main channels of agricultural product distribution. Geoffrey Shepheld (1942) discussed the results and reasons for the decentralization of agricultural product distribution. John W. Bennettl (1983) and others discussed how to better cooperate to adapt to the modern agricultural service system from the perspective of agricultural synergy. Kojo S. Amanor (2007) discusses the impact of modernization and mechanization of agricultural infrastructure on regional economies and local agricultural systems. Yanzhang (2008) studied the construction of agricultural product logistics system and information exchange based on technologies such as NET and WAP. Brahim Medjahed (2009) proposed a service-oriented infrastructure that can intelligently and timely share agricultural information, thereby improving agricultural information services. Ahumada (2009) conducted research on the integration of agricultural and food supply chains between two countries and many countries.

\section{DOMESTIC RESEARCH RELATED TO THE OVERALL}

\section{REQUIREMENTS OF RURAL REVITALIZATION STRATEGY}

Based on the overall requirements of the rural revitalization strategy, the related research is carried out from the four aspects of "logistics and rural industry, logistics and ecological civilization, logistics and (social) governance, logistics and (rich) life". The summary is as follows: 
Wang Xiaofang (2017) proposed the idea of constructing a green logistics innovation ecosystem.

\section{Research on the Relationship Between Logistics and Social Governance}

Tan Yi and Hu Zhengrong (2017) studied the external uneconomic governance of urban logistics in Nanning from the perspective of social governance. They also set out from three aspects of social governance functions, social development trends and the trend of deepening the reform of the economic system in China, and expounded the necessity of applying social governance theory to solve the external economic problems of urban logistics, and then proposed solutions from the four aspects of logistics center governance capabilities, industry autonomous governance capabilities, social supervision levels, governance technologies and methods through empirical research

Wang Jingyuan (2017) proposed the countermeasures of Inner Mongolia government's governance of the modern logistics industry from seven aspects, including establishing an effective logistics management coordination mechanism, creating a good logistics policy and legal environment, and playing the leading role of the Inner Mongolia government in logistics infrastructure construction. Wang Yiqun (2017) explored effective strategies to promote haze management through logistics industry upgrade, providing some references for reducing logistics costs, improving economic benefits, and saving energy and reducing emissions. Du Tao and Qiao Shunli (2017), taking Shenyang City as an example, analyzed the current situation of poor transportation and logistics in Shenyang, and analyzed the impact of Shenyang's economy and what effective governance strategies need to be adopted.

\section{Research on the Relationship Between Logistics and People's (Rich) Life}

Cui Xianshun (2016) took the development of the logistics industry in LY as an example, analyzed the current situation of the development of the logistics industry in LY, studied the development and changes of farmers 'prosperity in LY, and theoretically discussed the relationship between farmers' prosperity and the development of logistics. It provides a reference for guiding rural poverty alleviation and targeted poverty alleviation under the new situation. He explored the demand for logistics industry after farmers became affluent, and promoted the logistics industry to develop better and faster He studied the consumption level and consumption structure of farmers after they became affluent, and provided a basis for promoting the healthy development of various industries. Shen Jinsheng (2008) explored consumer logistics in modern urban life. Wang Weiming (2015) believed that there is a correlation between lifestyle changes and the output value of cold chain logistics. Zheng Xiaoli (2017) revealed the operational problems of consumer logistics serving the modern urban lifestyle service industry from the aspects of consumer logistics operation process management, operation mechanism design and operation organization function, and put forward new ideas such as strengthening the management of consumer logistics operation processes, designing innovative consumer logistics operation mechanisms, and optimizing the 
organizational functions of consumer logistics operations. Liang Wen and Zhang Wei (2016) believed that the overall level of urban-rural integration across the country is on the rise, and urban-rural integration, rural logistics and rural finance have significantly affected farmers' income. Urban-rural integration worked through the intermediary effects of rural logistics and rural finance. The three work together to increase farmers' income.

\section{RESEARCH SIGNIFICANCE OF THIS TOPIC}

Relevant research results in the areas of "Logistics and Rural Industry, Logistics and Ecological Civilization, Logistics and (Social) Governance, Logistics and (Wealthy) Life)" are very rich, showing research features of prominent focus, multiple perspectives, interdisciplinary collaboration and systematic innovation. However, after searching the related literatures, only two literatures on logistics research from the perspective of "village revitalization strategy" were found. One is to explore the path for Hua Huiting (2018) to build a rural e-commerce logistics ecosystem based on the strategy of rural revitalization. It proposes to form a new rural ecommerce logistics ecosystem based on the perspective of improving rural industrial structure and protecting rural industrial security. The other is for Xu Xiangyun (2018) to discuss the strategic background, prominent problems and fundamental guarantees of logistics in rural revitalization. The research has not been found that comprehensively combines rural revitalization strategies to carry out research on rural logistics industry and system construction.

Therefore, this topic draws on existing research foundations, comprehensively applies economics, management-related disciplines, and systems engineering theories and technical methods, selects the perspective of "Logistics and Rural Industries, Logistics and Ecological Civilization, Logistics and (Social) Governance, Logistics and (prosperous) life " to study the construction of rural logistics system in Hunan Province, puts forward its overall structure, implementation path, operation mode, safeguard measures and suggestions. It has a certain prospective and innovative value for enriching the theoretical research of logistics in China, and has a positive effect on promoting the modernization and development of rural logistics in Hunan Province. It is of practical significance to help realize the five overall requirements of "prosperous industries, ecological livability, rural civilization, effective governance, and wealthy life" in the rural revitalization strategy.

\section{THE OVERALl STRUCTURE OF THE STUDY}

It needs to construct a theoretical explanation framework for the construction of a rural logistics system in the context of a rural revitalization strategy. Research on rural logistics systems is on the rise. The proposal of the rural revitalization strategy puts forward new hopes, new requirements and new standards. It is necessary to define and theoretically analyze its basic concepts and establish structural systems and category descriptions. It requires the comprehensive application of economics, management, and other subject theories to build a theoretical explanation framework for the rural logistics system in the context of rural revitalization strategies.
It is a study of the current situation of Hunan rural logistics system based on the overall requirements in line with the rural revitalization strategy. Through in-depth investigation of key rural logistics enterprises in Hunan Province, in line with the implementation of the overall requirements of the five aspects of "prosperous industries, ecological livability, rural civilization, effective governance, and wealthy life" in the rural revitalization strategy, this paper conducts a systematic analysis to comprehensively grasp the main problems and development bottlenecks of the current rural logistics system in Hunan Province.

It is in line with the constructing the rural logistics system of Hunan Province in the new era in accordance with the overall requirements of the rural revitalization strategy. In line with the overall requirements of the five aspects of the rural revitalization strategy comprehensively, It builds a coordinated development logistics system with logistics and industry, cities and rural areas, production and life, employment and consumption, forward and reverse, realizing the prosperity of the rural industry and the prosperity of farmers. It advocates a green, low-carbon, environmentally friendly, and humane logistics operation model to create a rural, civilized, and ecologically livable environment. It promotes the standardized, standardized, modernized and institutionalized logistics service model, and realizes the overall structure of the construction of the rural logistics system in Hunan based on the integration of the logistics industry's own governance and rural governance.

It is the research of the specific implementation path of the construction of the rural logistics system in Hunan Province in the new era under the overall requirements of the rural revitalization strategy, and proposes safeguard measures and countermeasures.

\section{CONCLUSION}

This project will attempt to construct a theoretical explanation framework for the construction of a rural logistics system in the context of a rural revitalization strategy. In line with the overall requirements of five aspects of rural revitalization strategy, this article comprehensively grasps the main problems and development bottlenecks of the current rural logistics system in Hunan Province, and constructs a new era Hunan Rural Logistics System architecture. Then it studies the specific implementation path of rural logistics system construction in Hunan Province in the new era under the overall requirements of rural revitalization strategy, and puts forward and guarantee measures and countermeasures.

\section{REFERENCES}

[1] Wang Xinli. On the Structural Design of Rural Logistics System in China [J]. China Business and Market. 2003 (5). (in Chinese)

[2] Liu Yansui. Urban-rural Integration and Rural Revitalization in the New Era of China [J]. Journal of Geographical Sciences. 2018, Issue 04 (in Chinese)

[3] Wang Yahua, Su Yiqing. Rural Rejuvenation- A New Strategy for China's Rural Development [J]. Journal of the Central Institute of Socialism. 2017 (06) (in Chinese)

[4] Liu Heguang. Key Strategic Points and Path of Rural Rejuvenation [J]. China National Conditions and Strength. 2017 (12) (in Chinese) 